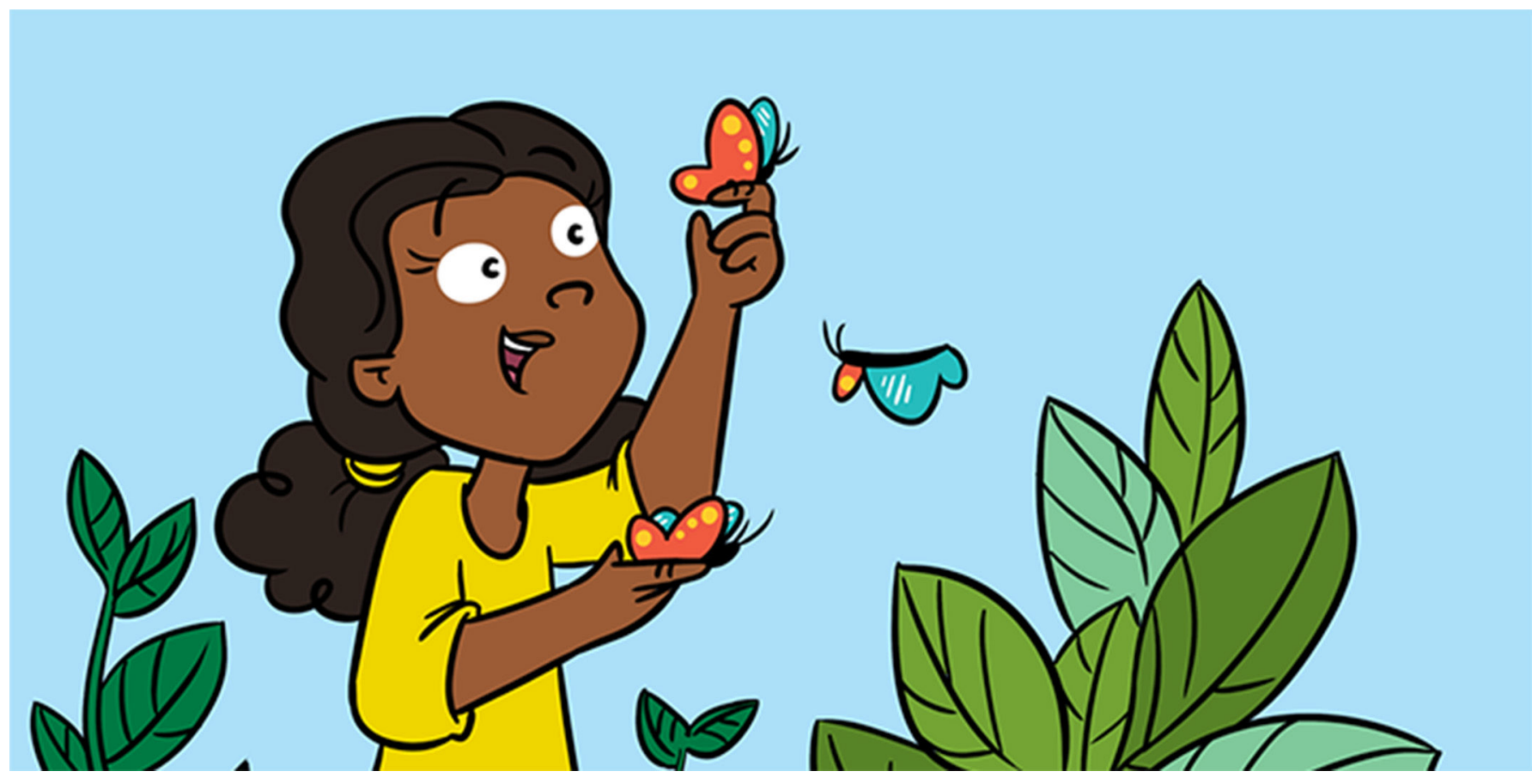

\title{
TWO SIDES TO A WING: A GENE THAT MAKES BUTTERFLY UPPER AND BOTTOM WING PATTERNS DIFFERENT
}

\section{Anupama Prakash*}

Department of Biological Sciences, National University of Singapore, Singapore, Singapore

YOUNG REVIEWERS:

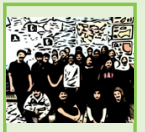

MERCY

SCHOOL

AGES: $12-15$
Butterflies, with their colorful and intricate wing patterns, have inspired artists and poets for many centuries. The variations in hues and patterns on their wings are not just for show but perform crucial communication functions. The patterns on the wings can help protect butterflies from predators through camouflage, or warn predators that the butterfly's body is toxic, or help attract potential mates. A major feature of these wing canvases is that they have two sides and they can contain different messages on each side. In general, butterflies use the upper surfaces of their wings to seduce the opposite sex, whereas they use the lower surfaces to hide from view or to communicate to their predators that eating them would be toxic. We have identified a gene that is responsible for creating the upper surface "seductive message" patterns. This gene, when mutated, transforms both surfaces of the butterfly wing into the lower surface wing pattern "anti-predation" message. This article discusses how we identified this butterfly wing gene that turns a two-sided canvas into a repeated one-sided canvas. 
Figure 1

(A) Two species of butterflies with different top/dorsal (left) and bottom/ ventral (right) wing surface patterns. The species to the left is the Orange Oakleaf butterfly (Kallima inachus) and the one to the right is Morpho aurora. Notice how the ventral surface of the Orange Oakleaf looks like a dried leaf (photographs: LepData. org). (B) Two examples of the final adult wing patterns and prepatterns seen on butterfly wings. Observe how the prepatterns closely match the final adult wing patterns. Images from Brunetti et al. [2] and Reed et al. [6].

(C) How are patterns created on butterfly wings? First there is an undivided, blank wing surface. Dorsal and ventral compartments are then created on the wing because of different expression of genes (Gene A shows the dorsal compartment, and the lack of Gene A creates the ventral

compartment). At this time, the wing is folded along the line so that the two surfaces are like the two sides of a paper. In the third box, you can see that prepatterns are then created in these compartments, again because of expression of different combinations of genes. As the last step, color appears within these pre-patterns. D, dorsal/ top; $\mathrm{V}$, ventral/bottom.
Have you ever looked at your finger and noticed that the two sides are different? One side has a nail and one side does not. Similarly, many of the features on your back are very different from the features on your belly side. This is true for most animals, including butterflies. Butterflies have wing patterns on one surface that are very different from the patterns on the other surface (Figure 1A). Butterflies often use dull colors and patterns on one of their wing surfaces, to hide from predators, and, showy colors on the other surface, to attract mates. In addition, because most butterflies usually sit with their wings closed, the ventral (or bottom) side of their wings, with the subdued colors, is the only visible surface. The dorsal (or upper) side with the showy colors becomes hidden when the wings are closed. Thus, butterflies can effectively hide from predators in this position, but still be able to open and flap their wings to display their hidden showy colors when courting potential mates. Think of a butterfly wing as a piece of paper that can have two very different messages written on either side, to be shown to different people.

\section{HOW DO WING PATTERNS DEVELOP IN BUTTERFLIES?}

What we wanted to understand by our experiments was how the different patterns on the two wing surfaces are created. But, before we go there, let us talk about how wings and their patterns develop in

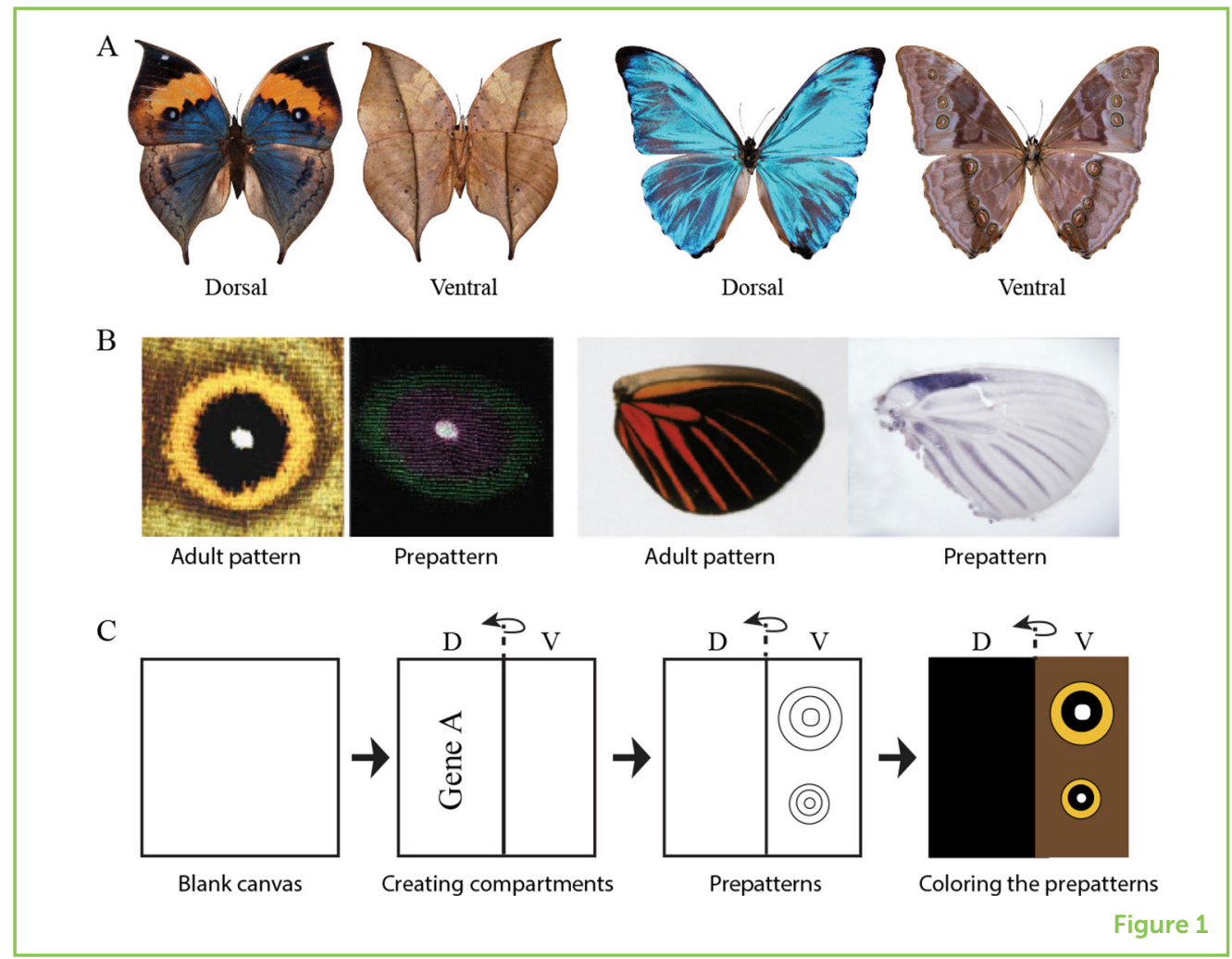




\section{HOLOMETABOLOUS}

A form of insect development that includes four life stages The life stages are: the embryonic stage (inside the egg), the larval (or caterpillar) stage, the pupal stage, and the adult stage.

\section{IMAGINAL DISCS}

Structures within the body of a

holometabolous insect larva that develop into the external structures of the adult (such as wings and legs).

\section{PREPATTERNS}

Patterns formed by groups of cells expressing different combinations of genes that finally regulate the development of different colors. butterflies and what we currently know about this process. Butterflies, along with beetles, flies, moths, and wasps, fall into the category of holometabolous insects. This means that butterflies go through a complete metamorphosis, which is the transition from a larval, grub-like animal to an adult animal with wings, large slender legs, and big eyes. Butterflies have four different life stages during development. These are the embryonic stage (which takes place inside the egg), the larval (or caterpillar) stage, the pupal stage, and the adult stage. Eggs are laid on the leaves of specific plants and the caterpillars that hatch from the eggs eat these leaves until they enter the pupal stage. The pupal stage is when most of the larval body tissues are dissolved and re-formed to create the adult butterfly that finally emerges. The wings of butterflies are formed from a group of cells that are set aside during the embryonic stage, in the form of imaginal discs. These imaginal discs grow inside the larval body as the larvae grow, but in the pupal stage the imaginal discs move to the outside of the body and develop their final size and shape. You can easily see the front wings of a future butterfly by carefully examining the two sides of a pupa.

Adult wing patterns gradually develop on the wing imaginal discs as these discs grow into the adult wings. At some point during the caterpillar stage, the wing is "divided" into dorsal and ventral compartments. This division happens because certain genes (sections of DNA that contain specific instructions to build the organism) become expressed only in one surface of the wing, say the dorsal surface, but not in the other. After this stage, prepatterns are laid out on the disc, due to the expression of different genes in different positions of the wing (Figure 1B). At this early stage, it is already clear that the prepatterns are different on the dorsal and ventral wing surfaces. In a later stage, colors appear in the prepatterns because pigmentation (color) genes become activated [1]. Using the analogy of a piece of paper again, we can create compartments in the paper by drawing lines and creating folds as shown in Figure $1 \mathrm{C}$. Then, we can draw a picture on one side of the paper that represents a prepattern, and finally we color the picture using different color combinations to get the final adult pattern (Figure $1 \mathrm{C}$ ).

Scientists have studied wing development in fruit flies (scientific name: Drosophila melanogaster) for many years and have identified a lot of genes important for creating compartments and patterns. Because wing development in fruit flies and butterflies is very similar, the initial stages of wing development, such as creation of compartments in butterfly wings, has come to be understood quite well through the study of fruit flies. However, butterflies are different from flies in that butterflies have intricate and colorful wing patterns. Researchers have been quite successful at identifying numerous genes that create these patterns. For example, many genes involved in the development of patterns that 
CRISPR-Cas 9

A new technology that helps scientists target specific genes to modify their sequence and gene functions. look like eyes, called eyespot patterns, have been identified. In the butterfly species Bicyclus anynana, genes called spalt and distal-less are expressed in the centers of eyespots, and, spalt is also expressed in the black ring. Another gene called engrailed/invected is expressed in the surrounding gold ring (Figure 1B) [2].

So, based on these studies and the similarity in development between fly and butterfly wings, we hypothesized that a gene called apterous $A$ might be responsible for creating different dorsal and ventral wing patterns in butterflies. We selected this gene because, in the wings of flies and butterflies, it is expressed only on the dorsal surface and is absent from the ventral surface $[3,4]$. We used the butterfly $B$. anynana to test this hypothesis. To show that this gene is responsible for creating different surface-specific patterns in butterflies, we needed to delete it and look at wing patterns in butterflies that did not have this gene. If apterous $A$ is indeed responsible for creating a dorsal pattern that is different from the ventral pattern, then when it is deleted, the dorsal pattern should become similar to the ventral pattern. To delete the apterous $A$ gene, we utilized a new technique called CRISPR-Cas9.

\section{WHAT IS THE CRISPR-Cas9 TECHNIQUE?}

The CRISPR-Cas9 technique is a powerful new technology that has made it possible for scientists to easily mutate genes and delete gene functions [5]. This system was initially identified in bacteria as an immune response to protect bacteria from harmful agents such as viruses [5]. When scientists use the CRISPR-Cas9 technique to delete certain genes in animals, they can then study the animals to see what happens when that gene is missing. The CRISPR-Cas9 technology basically consists of a molecular scissors (the Cas9 enzyme) that is guided to the gene of interest by a piece of RNA. RNA, similar to DNA, is a molecule that performs important biological functions within a cell. The RNA sequence tells the scissors which gene to chop up, and the Cas9 scissors cut it. However, repair mechanisms are quite poor and, when the chopped region is being repaired; lots of sequences either get deleted or added, destroying the function of that gene (Figure 2).

To use this system in $B$. anynana butterflies, we designed a RNA guide that recognizes the apterous $A$ gene in this species, and, we injected this sequence along with the Cas9 scissors into the eggs (Figure 2). We then raised all the emerging caterpillars until they became adults, and then studied the butterfly wing patterns to see if the dorsal patterns now looked like ventral patterns. The mutant patterns are usually mosaic (occur as patches on the wing surface) because only some cells (but not all the cells) of the butterfly would have been targeted by the 


\section{Figure 2}

Using the CRISPR-Cas9 technique in butterflies. A mixture of guide RNA and the Cas 9 molecular scissors is injected into butterfly eggs very early in development (top). The guide RNA directs the Cas9 to the correct gene and Cas9 cuts the DNA (middle). Since DNA repair mechanisms in these cases are not very efficient, many mutations appear at the target region. This makes the gene or DNA sequence nonfunctional and affects the final wing patterns. Since only some cells get mutated, the adult butterflies show mosaic patches where wing patterns are affected (bottom). DNA from these individuals can be double checked to see if mutations did occur in the targeted region.

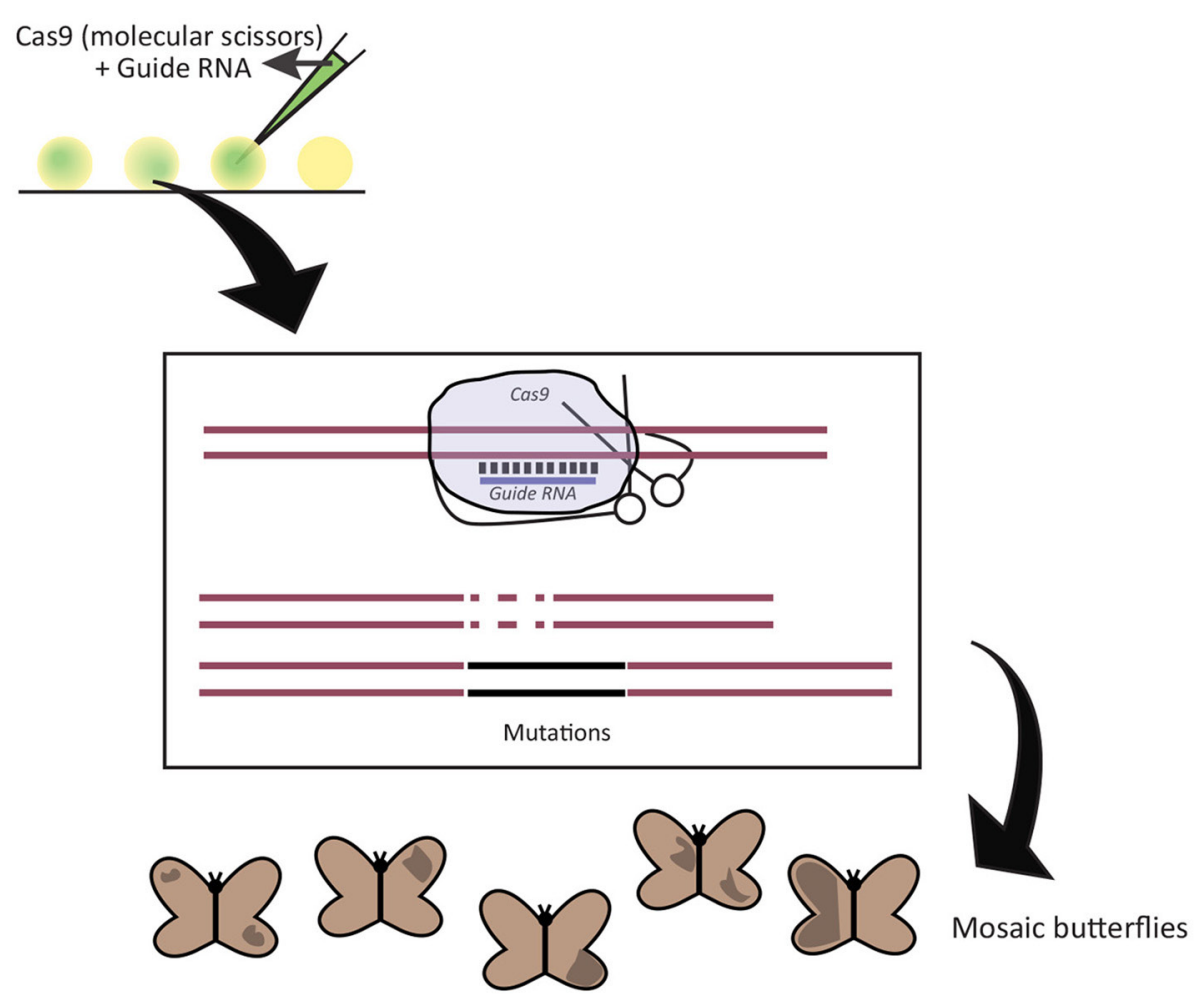

Figure 2

scissors when we injected them into the eggs (Figure 2). We can then confirm that the correct gene has been mutated by looking at the DNA of those butterflies to see whether the apterous $A$ gene sequence has been changed.

\section{APTEROUS A CREATES DORSAL-SPECIFIC BUTTERFLY WING PATTERNS}

We found that, when apterous $A$ was deleted from these butterflies, the butterflies had mosaic, ventral-like patterns on the dorsal surface of their wings (Figure 3) [6]. In the males for instance, certain features such as a gland used for producing courtship perfumes, which is normally located on the ventral surface, now appeared on the dorsal surface (red arrow in Figure 3, column 2). In addition, one butterfly showed ventral-like eyespot patterns (seven eyespots; red arrows in Figure 3, column 4) on the dorsal wing surface, that normally has only $0-2$ eyespots. When we analyzed the apterous $A$ gene sequence in these butterflies, we confirmed that the apterous $A$ sequence was changed. These results told us that apterous $A$ is indeed responsible for creating dorsal-specific wing patterns in butterflies. 
Figure 3

The normal (wildtype/ WT) dorsal and ventral wings of the butterfly Bicyclus anynana and the dorsal surfaces of mutants. Notice how the dorsal surfaces in mutants look like the ventral surfaces. You can see the appearance of the ventrally-located gland on the dorsal forewing surface (red arrow in column 2), all seven eyespots on the dorsal hindwing surface (red arrows in column 4) and mosaic patches on the dorsal surface indicated by white dotted lines. D, dorsal; $\mathrm{V}$, ventral. The mutants are all different butterflies.

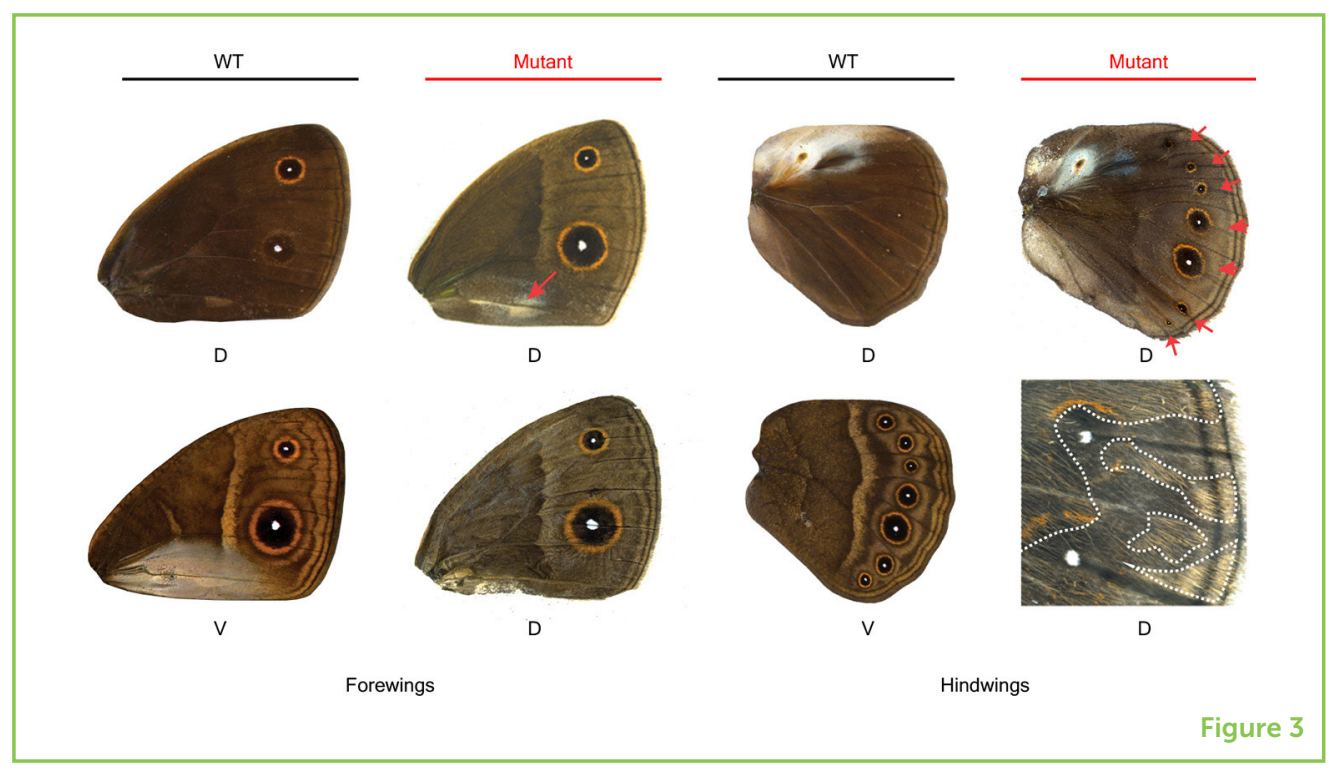

\section{WHERE DOES THIS DATA LEAD US?}

The diversity in surface-specific wing patterns in butterflies is enormous. If you ever visit a butterfly park or see the butterflies in your garden, you can notice this. We have identified a gene that can create these pattern variations between the dorsal and ventral wing surfaces of butterflies. Interestingly, the same gene (apterous) helps make beetle forewings very hard and solid. Other genes from the same family as apterous help to create different dorsal and ventral limb features in vertebrates such as mice. Thus, an interesting question that comes out of this work is whether the same family of genes is responsible for the different dorsalventral patterns in many different species, and how one gene family can create all this variation!

A second and possibly very interesting use of this data is as a tool to select cells that can be used to do other cool things. For instance, if you look at the very famous Morpho butterfly species (Figure 1A) you see that the dorsal side is a brilliant blue color while the ventral side is mostly brown. The blue color is very interesting to scientists, because it is not created by pigments but is due to a mechanism in which light interacts with very tiny structures on the surface of the wing scales. If apterous $A$ is expressed only on the dorsal surfaces, it means that all the cells that become blue scales express this gene. Using methods to sort out cells that express apterous $A$ and those that do not, we can separate only the blue scales and study how these cells make those tiny structures. This could then be used by scientists to create color-producing surfaces, or maybe even to modify living cells such as bacteria so that they can produce different colors! 


\section{ORIGINAL SOURCE ARTICLE}

Prakash, A., and Monteiro, A. 2018. apterous A specifies dorsal wing patterns and sexual traits in butterflies. Proc. R Soc. B Biol. Sci. 285:20172685. doi: 10.1098/rspb.2017.2685

\section{REFERENCES}

1. McMillan, W. O., Monteiro, A., and Kapan, D. D. 2002. Development and evolution on the wing. Trends Ecol. Evol. 17:125-33. doi: 10.1016/S0169-5347(01)02427-2

2. Brunetti, C. R., Selegue, J. E., Monteiro, A., French, V., Brakefield, P. M., and Carroll, S. B. 2001. The generation and diversification of butterfly eyespot color patterns. Curr. Biol. 11:1578-85. doi: 10.1016/S0960-9822(01)00502-4

3. Carroll, S. B., Gates, J., Keys, D. N., Paddock, S. W., Grace, E. F., Selegue, J. E., et al. 1994. Pattern formation and eyespot determination in butterfly wings. Science 265:109-14.

4. Cohen, B., McGuffin, M. E., Pfeifle, C., Segal, D., and Cohen, S. M. 1992. Apterous, a gene required for imaginal disc development in Drosophila encodes a member of the LIM family of developmental regulatory proteins. Genes Dev. 6:715-29.

5. Sander, J. D., and Joung, J. K. 2014. CRISPR-Cas systems for editing, regulating and targeting genomes. Nat. Biotechnol. 32:347-55. doi: 10.1038/nbt.2842

6. Reed, R. D., Papa, R., Martin, A., Hines, H. M., Kronforst, M. R., Chen, R., et al. 2011. optix Drives the repeated convergent evolution of butterfly wing pattern mimicry. Science 333:1137-41. doi: 10.1126/science.1208227

SUBMITTED: 21 April 2018; ACCEPTED: 16 November 2018;

PUBLISHED ONLINE: 06 December 2018.

EDITED BY: Sophie von der Heyden, Stellenbosch University, South Africa

CITATION: Prakash A (2018) Two Sides to a Wing: A Gene That Makes Butterfly Upper and Bottom Wing Patterns Different. Front. Young Minds 6:68. doi: 10.3389/ frym.2018.00068

CONFLICT OF INTEREST STATEMENT: The author declares that the research was conducted in the absence of any commercial or financial relationships that could be construed as a potential conflict of interest.

COPYRIGHT @ 2018 Prakash. This is an open-access article distributed under the terms of the Creative Commons Attribution License (CC BY). The use, distribution or reproduction in other forums is permitted, provided the original author(s) and the copyright owner(s) are credited and that the original publication in this journal is cited, in accordance with accepted academic practice. No use, distribution or reproduction is permitted which does not comply with these terms. 


\section{YOUNG REVIEWERS}

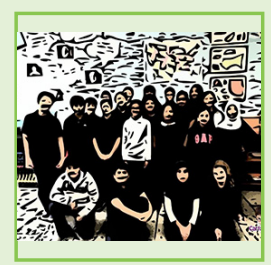

\section{MERCY SCHOOL, AGES: 12-15}

Our teacher says we are an energetic and bright group. We love STEAM and do fantastic when it comes to projects and research. We are most excited to learn about science and see its applications.

\section{AUTHOR}

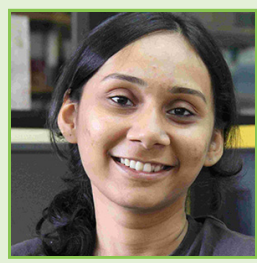

\section{ANUPAMA PRAKASH}

As a kid, I loved biology and learning about how animals and plants grew and functioned. I was also passionate about art because my mom would keep making me do fun, art and crafts projects during my free time. This early childhood exposure eventually led me to become a scientist, studying how colors and patterns develop in butterflies. I am always on the lookout for projects that combine art and science. Outside work, I love sketching, playing badminton and scuba diving! *anupama@u.nus.edu 